\title{
Moral distress and Burnout syndrome: are there relationships between these phenomena in nursing workers? ${ }^{1}$
}

\author{
Graziele de Lima Dalmolin² \\ Valéria Lerch Lunardi3 \\ Guilherme Lerch Lunardi ${ }^{4}$ \\ Edison Luiz Devos Barlem ${ }^{5}$ \\ Rosemary Silva da Silveira ${ }^{5}$
}

\begin{abstract}
Objective: to identify relationships between moral distress and Burnout in the professional performance from the perceptions of the experiences of nursing workers. Methods: this is a survey type study with 375 nursing workers working in three different hospitals of southern Rio Grande do Sul, with the application of adaptations of the Moral Distress Scale and the Maslach Burnout Inventory, validated and standardized for use in Brazil. Data validation occurred through factor analysis and Cronbach's alpha. For the data analysis bivariate analysis using Pearson's correlation and multivariate analysis using multiple regression were performed. Results: the existence of a weak correlation between moral distress and Burnout was verified. A possible positive correlation between Burnout and therapeutic obstinacy, and a negative correlation between professional fulfillment and moral distress were identified. Conclusion: the need was identified for further studies that include mediating and moderating variables that may explain more clearly the models studied.
\end{abstract}

Descriptors: Nursing; Ethics, Nursing; Nursing, Team; Burnout, Professional.

\footnotetext{
${ }^{1}$ Paper extracted from doctoral dissertation "Moral distress and burnout syndrome: relations in nursing staff's day-to-day working experiences 2012", presented to Universidade Federal do Rio Grande, Rio Grande, RS, Brasil. Supported by Conselho Nacional de Desenvolvimento Científico e Tecnológico (CNPq), process \#475366/2008-5.

${ }_{2}^{2}$ PhD, Adjunct Professor, Departamento de Enfermagem, Universidade Federal de Santa Maria, Santa Maria, RS, Brazil.

${ }^{3} \mathrm{PhD}$, Associate Professor, Departamento de Enfermagem, Universidade Federal de Santa Maria, Santa Maria, RS, Brasil.

${ }^{4}$ PhD, Adjunct Professor, Instituto de Ciências Econômicas, Administrativas e Contábeis, Universidade Federal do Rio Grande, Rio Grande, RS, Brasil.

${ }^{5} \mathrm{PhD}$, Adjunct Professor, Escola de Enfermagem, Universidade Federal do Rio Grande, Rio Grande, RS, Brasil.
}

Corresponding Author:

Graziele de Lima Dalmolin

Universidade Federal de Santa Maria

Departamento de Enfermagem

Av. Roraima, 1000, Prédio 26A, Sala 1305B

Camobi

CEP: 97105-900 Santa Maria, RS, Brasil

Email: grazi.dalmolin@gmail.com
Copyright (๑) 2014 Revista Latino-Americana de Enfermagem This is an Open Access article distributed under the terms of the Creative Commons Attribution Non-Commercial License (CC BY-NC).

This license lets others distribute, remix, tweak, and build upon your work non-commercially, and although their new works must also acknowledge you and be non-commercial, they don't have to license their derivative works on the same terms. 


\section{Introduction}

Currently, great emphasis is given to the experiences of healthcare and nursing workers in relation to ethical issues and conflicts. These situations, involving divergences from one or more values, with uncertainties about the correct course of action to be followed, demanding decision-making and confrontations on behalf of the workers, can be identified as ethical issues $^{(1)}$.

Initially, three categories of ethical issues affecting nurses were identified, moral distress, moral uncertainty, and moral dilemmas. In situations of moral distress, employees recognize the ethically appropriate action, however, feel unable to act according to their conscience due to fear or circumstances beyond their ability, possibly leading to a compromise in their values and identity as moral agents. Moral uncertainty occurs when the professional does not know the ethically correct course of action, however, has a feeling of uncertainty, a feeling that something is not right. Finally, moral dilemmas occur when there are two or more opposing action options, which can equally ethically justify the agent, who is unable to perform both actions and is faced with a dilemma when having to choose a course action to follow as there is not an argument strong enough to indicate one option over another(2). From this perspective, the discussion of these issues becomes relevant as, according to the Professional Nursing Code of Ethics (CEPE), it is the responsibility and duty of the nursing workers to ensure care free of damage originating from malpractice, negligence and recklessness, at the individual or collective level. This is because nursing is structured under its own set of technical and scientific knowledge, involving a commitment to the health and quality of life of individuals, families and the community, in line with the ethical and legal considerations ${ }^{(3)}$.

Circumstances associated with moral problems and moral distress can be encountered by nursing workers in their daily work, as well as in situations of questionable professional practices; therapeutic obstinacy; unequal distribution of resources ${ }^{(4-5)}$; work overload; and when there is disregard for their opinions in decision making, since the staff develop feelings of frustration and helplessness due to the difficulty in influencing their working conditions( ${ }^{(6)}$.

These manifestations related to moral distress and to confronting ethical situations in the nursing quotidian are quite similar to those mentioned in the literature related to stress and Burnout ${ }^{(7)}$. Burnout is a complex and multifaceted phenomenon that affects aspects of the well-being of healthcare workers and the quality of care provided(8) and consist of the dimensions of emotional exhaustion (or exhaustion, characterized as an individual response to stress, such as feeling fatigue), depersonalization (or cynicism regarding the negative reaction to others and the work) and reduced professional fulfillment (or professional ineffectiveness, understood as a negative evaluation of their own achievements in the work) ${ }^{(9)}$.

Moral distress and Burnout have appeared associated with the performance of the nurse's role as the advocate of the patient, being identified as potential sources of these dilemmatic phenomena of care versus cure, conflicts between legal and ethical obligations, perceived powerlessness, power differences, excess responsibility of nurses because of an insufficient number of workers in the nursing team, a perception of inadequate medical treatment, and an aggressive style of communication by the medical team ${ }^{(10)}$.

Although the nursing workers recognize the necessity to provoke questioning faced with moral problems, they can reveal themselves to be fearful of doing this, possibly due to the inequality of power experienced in the work environments ${ }^{(11)}$, in the nursing team itself, and in the institution as a whole, despite the implications for the users, which can be strongly associated with Moral Distress and Burnout Syndrome. Thus, the aim of this study was to identify relationships between moral distress and Burnout in the professional performance from the perceptions of the experiences of nursing workers.

\section{Methodology}

This was a survey study conducted in three hospitals $(\mathrm{H} 1, \mathrm{H} 2$, and $\mathrm{H} 3)$ of southern Rio Grande do Sul, located in two different municipalities (M1 and M2). Institution $\mathrm{H} 1$ is a public federal university hospital with 186 beds and has 314 nursing workers, the majority being public workers contracted through the public examination process (Regime Jurídico Único). Institution $\mathrm{H} 2$ is a philanthropic hospital with 658 beds, in which 417 nursing workers operate, contracted through the Consolidation of Labor Laws process (Consolidação das Leis do Trabalho - CLT). Institution $\mathrm{H} 3$ is a philanthropic public teaching hospital with 291 beds and a staff of 482 nursing workers, also employed through the CLT process.

For data collection, two instruments were used, the first to investigate moral distress, an adaptation 
of the Moral Distress Scale (MDS), and the second to investigate Burnout, an adaptation of the Maslach Burnout Inventory (MBI). A component to characterize the subject was also included in the instrument. The MDS was originally developed in the North American context ${ }^{(12)}$ and was subjected to the process of reverse translation, cultural adaptation and validation(4) when it was realized that the situations identified in our reality as sources of moral distress were not adequately addressed, with it being adapted to consider these particularities $^{(13)}$. The questionnaire was composed of 39 questions, using a Likert type scale of seven points to assess the intensity and frequency of moral distress.

The other instrument used was an adaptation of the MBI, which went through the process of translation, adaptation and semantic validation, as well as validation and standardization for use in Brazil, in the Psychology of Work Laboratory of the National University of Brasilia (UNB) ${ }^{(14)}$. The questionnaire consists of 22 items evaluated and divided into three subscales: emotional exhaustion, professional fulfillment, and depersonalization. The response options were also on a Likert type scale of seven points.

The research subjects were the nursing workers of $\mathrm{H} 1, \mathrm{H} 2$ and $\mathrm{H} 3$. As the total number of workers in these institutions was 1213 individuals, a sample size selection formula was used(15), which estimated the minimum number of 295 subjects for the performance of the statistical analysis. The inclusion criteria of the subjects considered the availability and interest in answering the instrument at the moment of data collection, constituting a non-probabilistic convenience sample. The questionnaires were self-administered, i.e., the members of the research team delivered the questionnaires to the place of practice of the research subjects, explaining how to participate in the study and scheduling the date for the collection of the material. Those who made themselves available to participate were handed a manila envelope containing the study instruments and two copies of the terms of free prior informed consent, so that the participant could respond to the instruments in the location of their choice. The return of the instruments occurred through scheduling according to the availability of the participant to return them completed, with up to five attempts being made.

Data collection was carried out from October 2010 to July 2011. A total of 500 questionnaires were delivered to the nursing workers, with 387 instruments returned. It should be noted that this number would have changed if other nursing workers, who at the time of data collection were not found, had expressed an interest or later sought out the researchers in order to participate in the study. The exclusion criteria also adopted for the analysis procedures were, those respondents who, in the two instruments, used only two points of the scale, altering the adopted scale interval, and those who left more than ten items unanswered. Thus, with the exclusion of 12 instruments, the final sample for data analysis was composed of 375 subjects.

After the data collection, two statistical tests were performed to ensure the validity of the instrument, factor analysis and Cronbach's alpha. The data analysis was performed through bivariate analysis using Pearson's correlation, seeking to summarize the strength of association between two variables (in this case moral distress and Burnout) and measure the possibility that the variation in one of them may be associated with the variation in the other ${ }^{(16)}$. The strength of the association presented by the correlation coefficient can be classified according to the intensity of the correlation, which ranges from -1 to +1 . The strength of association is classified according to the coefficient variation, as shown below: values between \pm 0.91 and \pm 1.00 are considered very strong; between \pm 0.71 and \pm 0.90 , strong; between \pm 0.41 and \pm 0.70 , moderate; between \pm 0.21 and \pm 0 40 , weak, but defined; and between \pm 0.01 and \pm 0.20 , weak, almost imperceptible ${ }^{(16)}$.

The second type of analysis, used to analyze the relationship between a dependent variable and various independent variables, was multivariate multiple linear regression. This type of analysis can describe and predict relationships between two or more metric variables - making it possible to verify the influence of different aspects of moral distress on Burnout and the aspects of Burnout on moral distress ${ }^{(16)}$. The Statistical Package for the Social Sciences (SPSS) version 13.0 software was used.

All ethical considerations for research involving humans were respected and the study was approved by the local Research Ethics Committee (Protocol No. 70/2010).

\section{Results}

Regarding the characteristics of the study sample $(n=375)$, it was found that 31 subjects were nursing assistants, 268 were nursing technicians and 76 were nurses. The mean age of the subjects was 34 years, ranging between 19-64 years. Of the total subjects, $325(86.7 \%)$ were female, $44(11.7 \%)$ male, and six 
subjects $(1.6 \%)$ did not answer this question. In relation to the place of work $70(18.7 \%)$ subjects worked in $\mathrm{H} 1,197$ (52.5\%) in $\mathrm{H} 2$, and 108 (28.8\%) in $\mathrm{H} 3$. The subjects presented a mean time of 5.6 years working in the institution, and 3.8 years working in the unit.

From the factor analysis of the moral distress evaluation instrument, it was possible to validate 20 of the 39 initially proposed questions. The criteria adopted for the removal of items were, firstly, the process of gradual exclusion of each of the questions that presented low correlations in their blocks (low factor loading, less than 0.40), then those that presented a high factor loading in more than one factor (higher than 0.40) and, finally, those that did not present conceptual coherence with the constructs formed, thus, a total of 19 questions were excluded. The 20 validated questions were grouped in four dimensions: lack of competence in the work team, disrespect for patient autonomy, inadequate working conditions, and therapeutic obstinacy. The factor analysis of the Burnout evaluation instrument allowed 17 of the 22 proposed questions to be grouped according to the three dimensions of Burnout: emotional exhaustion, professional fulfillment, and depersonalization, five being excluded due to low factor loadings (less than 0.40), not presenting conceptual coherence with the group, or for forming isolated blocks.

The Kaiser-Meyer-Olkin measure verified the adequacy of the sample for the analysis, presenting a value of 0.944 for the moral distress instrument and 0.840 for the Burnout instrument. In the moral distress instrument, the four dimensions proposed explained $71.72 \%$ of the variance of the original questions, while in the Burnout instrument the three dimensions explained $49.31 \%$ of the variation, representing an adequate degree of synthesis of the data, facilitating its handling and interpretation.

The Cronbach alpha of the moral distress instrument presented a value of 0.95 , while the coefficients of each of the four dimensions ranged between 0.78 and 0.96 . The Burnout instrument presented a Cronbach's alpha value of 0.61 , and its dimensions presented values between 0.72 and 0.85 . As values between 0.60 and 0.80 are suggested for exploratory studies, the reliability of the two instruments and their identified dimensions was proven.

Through the Pearson's Correlation analysis, the aim was to investigate the association between the moral distress and Burnout variables, and to identify whether the variation in one of these could be associated with the variation in another. It was observed that the relationship between moral distress and Burnout is significant (at 5\%) and positive, however weak, almost imperceptible ${ }^{(16)}$, as summarized in Table 1.

Table 1 - Pearson's Correlation Results, Rio Grande, RS, Brazil, 2012

\begin{tabular}{llcc}
\hline & Burnout & $\begin{array}{c}\text { Moral } \\
\text { distress }\end{array}$ \\
\hline Burnout & Pearson's correlation & 1 & $0.102^{*}$ \\
& P & & 0.049 \\
Moral distress & N & 375 & 374 \\
& Pearson's correlation & $0.102^{*}$ & \\
& P & 0.049 & \\
& N & 374 & 374 \\
\hline
\end{tabular}

*Significant correlation at 5\%

Thus, with the identification of the presence of correlation between moral distress and Burnout, multiple regression analysis was performed in order to identify the main factors that contribute to the development of Burnout, considering the different dimensions of moral distress. Multiple regression was also used to verify the converse, i.e., to seek to determine which factors contribute to moral distress, considering Burnout. The representation of the two regression analyzes can be seen in Figure 1.

There were two regression analyzes, the first considering Burnout as the dependent variable and the second considering moral distress as the dependent variable. First, the effect of the four dimensions of moral distress on Burnout were evaluated, with the model tested not presenting statistical significance $(p=0.128)$, with a very low adjusted coefficient of determination $\left(R^{2}=0.009\right)$. These results can be seen in Table 2 .

Considering Table 2, it is possible to observe that none of the dimensions associated with moral distress significantly contribute to the development of Burnout, with only therapeutic obstinacy having a value close to the limit of $5 \%$. In this case, there seems to be proximity in relation to therapeutic obstinacy influencing the development of Burnout, i.e., nursing workers who experience situations of greater therapeutic obstinacy seem more prone to the development of Burnout.

In the second regression analysis the effects of the three dimensions of Burnout on the occurrence of moral distress were evaluated, as defined in Figure 2. The model was also not statistically significant $(p=0.086)$, presenting a very low adjusted coefficient of determination $\left(R^{2}=0.010\right)$. This coefficient, which varies from 0 to 100 , represents the degree of explanation of the proposed model, considering the independent and 
dependent variables used. In this case, it is clear that both Burnout and moral distress can not be explained by each other, with other mediator or moderator variables which were not tested in this model possibly existing that explain this relationship. The results of this regression analysis can be seen in Table 3 .
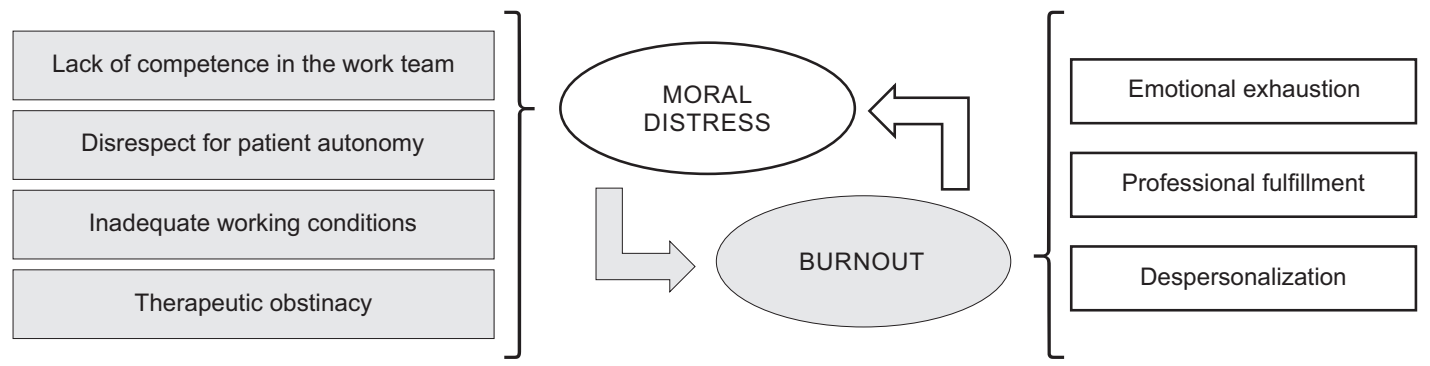

Figure 1 - Representation of factors of moral distress that can contribute to the development of burnout, and of factors of burnout that can contribute to the development of moral distress

Table 2 - Regression Analysis between the dimensions of moral distress according to burnout - Rio Grande, RS, Brazil, 2012

\begin{tabular}{lcc}
\hline \multicolumn{1}{c}{ Dimensions } & Beta & $\boldsymbol{p}$ \\
\hline Lack of competence in the work team & -0.003 & 0.950 \\
Disregard for patient autonomy & 0.037 & 0.476 \\
Inadequate working conditions & 0.088 & 0.091 \\
Therapeutic obstinacy & 0.101 & 0.051 \\
\hline
\end{tabular}

Table 3 - Regression Analysis between the dimensions of burnout regarding moral distress - Rio Grande, RS, Brazil, 2012

\begin{tabular}{lcc}
\hline \multicolumn{1}{c}{ Dimensions } & Beta & $\boldsymbol{p}$ \\
\hline Emotional exhaustion & 0.077 & 0.139 \\
Professional fulfillment & -0.107 & $0.039^{*}$ \\
Depersonalization & 0.022 & 0.670 \\
\hline *Value statistically significant at 5\% & &
\end{tabular}

*Value statistically significant at $5 \%$

When observing Table 3, it is clear that, although the model has a low level of explanation, one of the dimensions of Burnout associated with moral distress was statistically significant. In this case, it is possible to say that professional fulfillment negatively influences moral distress, showing that the higher the professional fulfillment, the lower the moral distress.

\section{Discussion}

Considering the findings it was possible to perceive that there is a significant, although weak, positive relationship between moral distress and Burnout. Among the possible relationships between these phenomena, moral distress triggered by situations of therapeutic obstinacy seems to be associated with the development of Burnout, as there is a relationship very close to the significance level of $5 \%$, however, further studies with different samples are required to confirm or reject this.

Therapeutic obstinacy consists of the implementation of therapeutic measures recognized by the nursing workers as futile and responsible for prolonging the suffering of terminally ill patients(5). Moral distress resulting from therapeutic obstinacy, which seems to have an influence on the development of Burnout, refers to situations contemplated in the questions of the instrument that comprised this item, i.e., q05 - To initiate intensive procedures to save the life, when it is believed that they merely delay the death; q11 - To provide assistance to physicians who are performing procedures on patients after cardiac recovery was unsatisfactory; and q12 - To issue medical prescriptions to conduct unnecessary tests and treatments with terminally ill patients.

Accordingly, proximity between moral distress and Burnout has been identified related to activities of the nurse as the advocate of the patient, especially in behaviors that involve perceptions of futile care. Specifically, moral distress was also identified due to the negation of the role of the nurse as the advocate of the terminally ill patient, i.e., when nurses present difficulties in acting in the defense of the rights of terminally ill patients ${ }^{(13)}$, which may also be associated with Burnout due to the fact that it involves the provision of futile care. The two phenomena, moral distress and Burnout separately present manifestations that may be responsible for nursing workers leaving the profession, also denoting possible proximity ${ }^{(10,17)}$. 
It was also noted that moral distress and possible Burnout resulting from therapeutic obstinacy and the provision of futile care by nursing workers may be associated with difficulties in sharing opinions regarding clinical decisions. In the multidisciplinary teams, other members, such as physicians, often represent and exercise greater power, with the knowledge of the nursing workers frequently undervalued, limiting them to participating informally in the decision making process at the bedside of patients due to the rigid and formal structure of decision making in the institutions ${ }^{(17)}$. These types of experiences of the nursing workers, such as clinical decision-making and organizational issues, add to feelings of their work not being valued and recognized, adding to the lack of autonomy and inability to provide quality care to patients, primarily due to difficulty having their statements, knowledge and role as patient advocate recognized and accepted $^{(18)}$.

In a certain way, the nursing workers seem to face resistance difficulties, in their work environments, especially in the situations that generate deterioration and moral distress. By analyzing the questions that composed the therapeutic obstinacy dimension, it was possible to see that moral distress occurs when the nursing workers perform procedures they believe to be unnecessary, thus acting against their own values and knowledge, which can also be associated with the development of Burnout. From this perspective, the importance of pastoral power and disciplinary power are emphasized. Power is understood as the multiplicity of force relations immanent and constitutive in the place in which they operate, as a constant game of struggle and confrontations that transforms them, that is, they are relationships that constitute a continuous confrontation, through strategies and techniques ${ }^{(19)}$.

Pastoral power is exercised over bodies and populations, through techniques such as the direction of conscience and obedience, leading individuals to their own mortification, the renunciation of the world and of themselves. Thus, mortification is a form of relationship with oneself. In nursing, pastoral power refers to nurses' actions which are based predominantly in obedience, resignation and self-denial, distancing these workers from their political competences and from confronting situations with the team or institution(20). Acting in consonance with pastoral power, there is also the power to discipline, which has as its goal the formation of docile and useful bodies, i.e., it acts in the subjection of forces of the individuals, giving them a relationship of docility-utility, i.e., as their economic utility increases, their political capacity and the ability to revolt, resist, and struggle and the counter-power reduces ${ }^{(21)}$.

Therapeutic obstinacy associated with moral distress and Burnout in nursing, seems to relate mainly to the difficulties of the workers to express their opinions and take a more active role in the decision-making processes together with the multidisciplinary team, which seems to be associated with the moral construction of these workers, with the valorization of obedience and, in contrast, the normalizing sanction of the resistance. With the perception of their work and opinions devalued, when not participating in decision-making related to the best care for the patient, the nursing workers may feel helpless and without autonomy to confront these moral conflicts, with difficulties to implement the care they consider to be correct. These differences in the exercise of power are recognized as a sources of conflict for the majority of these workers, contributing significantly to their inability to effectively advocate for their patients, relegating to second place this attribute due to institutional constraints, family expectations, and medical opinions(22).

Also associated with these issues, is another finding of this study, which demonstrates a significant negative correlation between professional fulfillment and moral distress, that is, with an increase in professional fulfillment, indicating a lower possibility of Burnout, there is also a decrease in moral distress. The professional fulfillment dimension is explained from the seven questions that compose it, these being: 4 - I feel stimulated after working side by side with my clientele; 6 - In my work, I deal with emotional problems very calmly; 11 - I can easily create a calm environment with my clientele; 12 - I feel that I am positively influencing other people's lives through my work; 15 - I adequately treat the problems of my clientele; 18 - I can easily understand what my clients feel about things; and 22 - I have carried out many important things in this work.

When considering the issues presented, it can be said that the confrontations of the nursing workers are relevant and necessary for the maintenance of professional fulfillment, so that they feel respected, valued and stimulated in their work environments, and that, as evaluated, they can positively influence the lives of their patients. Furthermore, it is possible to observe that, among the results presented, there is a perceived coherence, through the experiences of the nursing workers in relation to their actions that can influence 
the occurrence of moral distress and Burnout. It was perceived that when the workers express professional fulfillment, i.e., feel that their expectations at work, their needs and values are realized, they present lower possibilities of developing moral distress and Burnout, unlike when experiencing therapeutic obstinacy, in which a devaluation of their knowledge and values seems to occur, increasing the possibility of moral distress and Burnout.

\section{Final Considerations}

It can be observed that there is a correlation, even though classified as low, between moral distress and Burnout. It should be noted that, through the findings, it was not possible to establish cause and effect between these two phenomena, since the models presented were not significant and presented very low levels of explanation, i.e., the relationship of cause and effect could be due to other variables that were not tested, such as the characteristics and profile of the respondent, job satisfaction, and interest in changing sector or leaving the profession.

Although the models presented were not significant, some correlations between the dimensions of moral distress and Burnout were observed. When analyzing the influence of the dimensions of moral distress on Burnout, it was noted that therapeutic obstinacy presented a significance level very close to acceptable, which is in line with some approximations between the two phenomena already highlighted in the literature, which relate the provision of futile care and the non-performance of the nurse as the patient advocate. Regarding the dimensions of Burnout associated with moral distress, a significant negative relationship between professional fulfillment and moral distress was found, i.e., with an increase in professional fulfillment there is a decrease in the perception of moral distress.

These findings, together with the analysis of the questions of the instruments, refer to the need for nursing workers to confront situations in their work places, strengthening their knowledge, values and beliefs, as well as their perception of what is the best care for their patients, i.e., not acting on behaviors they consider unsuitable, thus maintaining their professional fulfillment. This study presented some limitations such as the non-inclusion of mediating and moderating variables that could contribute to better explain the relationship between moral distress and Burnout in nursing workers.
This leads to the suggestion that these are sought and tested in further studies, which could also use different samples, for example, random samples.

\section{References}

1. Canadian Nurses Association. Code of ethics for registered nurses. Ottawa, Canada: Centennial Ed; 2008.

2. Jameton A. Nursing Practice: The ethical issues. Prentice-Hall: Englewood Cliffs; 1984.

3. Conselho Federal de Enfermagem (BR). Resolução no 311/2007 - Aprova a Reformulação do Código de Ética dos Profissionais de Enfermagem. Rio de Janeiro 8 fev 2007.

4. Barlem ELD, Lunardi VL, Lunardi GL, Dalmolin GL, Tomaschewski JG. Vivência de sofrimento moral na enfermagem: percepção da enfermeira. Rev Esc Enferm USP. 2012;46(3):681-8.

5. Carvalho KK, Lunardi VL. Therapeutic futility as an ethical issue: intensive care unit nurses. Rev. LatinoAm. Enfermagem. 2009;17(3):308-13.

6. Silén M, Tang PF, Wadensten B, Ahlström G. Workplace distress and ethical dilemmas in neuroscience nursing. J Neurosci Nurs. 2008;40(4):222-31.

7. Rodney $P$, Starzomski R. Constraints on the moral agency of nurses. Can Nurse. 1993;89(9):23-6.

8. Peterson $U$, Demerouti $E$, Bergström G, Samuelsson M, Asberg M, Nygren A. Burnout and physical and mental health among Swedish healthcare workers. J Adv Nurs 2008;62:84-95.

9. Maslach C. Understanding Burnout: Work and family issues. In: Halpern DF, Murphy SE. (Eds). From workfamily balance to work-family interation: Changing the metaphor. Mahwah, NJ: Erlbaum; 2005.

10. Sundin-Huard D, Fahy K. Moral distress, advocacy and Burnout: theorizing the relationships. Int J Nurs Pract. 1999;5: 8-13.

11. Foucault M. História da sexualidade II: O uso dos prazeres. São Paulo: Graal; 1984.

12. Corley MC, Elswick RK, Gorman M, Clor T. Development and evaluation of moral distress scale. J Adv Nurs. 2001;33(2):250-6.

13. Barlem ELD. Sofrimento moral reconfigurado: uma visão foucaultiana [tese de doutorado]. Rio Grande (RS): Escola de Enfermagem da Universidade Federal do Rio Grande; 2012. 191 p.

14. Tamayo MR. Validação do Inventário de Burnout de Maslach (Resumo). In: Sociedade Brasileira de Psicologia. 26 Reunião Annual de Psicologia, 23 out - 27 out 1996; Ribeirão Preto. Ribeirão Preto: SBP; 1996. p. 153. 
15. Hill MM, Hill A. Investigação por questionário. Lisboa:

Editora Sílado; 2002.

16. Hair JF, Anderson RE, Tatham RL, Black WC. Análise multivariada de dados. Porto Alegre: Artmed; 2005.

17. Austin W, Kelecevic J, Goble E, Mekechuk J. An overview of moral distress and the pediatric intensive care team. Nurs Ethics. 2009;16(1):57-68.

18. Dalmolin GL, Lunardi VL, Barlem ELD, Silveira RS. Implicações do sofrimento moral para os(as) enfermeiros(as) e aproximações com o Burnout. Texto Contexto Enferm. 2012;21(1):200-8.

19. Foucault M. História da sexualidade I. A vontade de saber. 19 ed. Rio de Janeiro: Edições Graal; 1988.

20. Foucault M. Ditos e escritos IV. Estratégia, PoderSaber. Rio de Janeiro: Forense Universitária; 1994.

21. Foucault M. Vigiar e Punir: nascimento da prisão. 36 ed. Petrópolis: Vozes; 2009.

22. Tang PF, Johansson C, Wadensten B, Wenneberg S. Chinese nurses' ethical concerns in a neurological ward. Nurs Ethics. 2007;14(6):810-24. 